\title{
CORPORATE WORKERS' IMAGES OF FARMING AND STRESS ALLEVIATION THROUGH GARDENING ACTIVITIES: A CASE STUDY OF ONE-DAY GARDENING TOUR IN A SUBURB OF TOKYO
}

\author{
Koji Marutani $^{*}$, Takuji Yamaguchi ${ }^{2}$, Ailing $\mathbf{H u}^{2}$, Yoshibumi Chiba ${ }^{2}$, Akio \\ Mizushima $^{2}$, Koichi Ikegami', Tadasu Tsuruta ${ }^{1}$ \\ ${ }^{1}$ Graduate School of Agriculture, Kindai University, 3327-204 Nakamachi, Nara, 631-8505, \\ Japan \\ ${ }^{2}$ Graduate School of Medicine, Juntendo University, 2-1-1, Hongo, Bunkyo-ku, Tokyo 113- \\ 8421 Japan \\ *Corresponding author: e-mail: 1644680005a@nara.kindai.ac.jp
}

Citation: Marutani K., Yamaguchi, T., Hu, A., Chiba, Y., Mizushima, A., Ikegami, K., and Tsuruta, T. 2020. Corporate Workers' Images of Farming and Stress Alleviation through Gardening Activities: A Case Study of Gardening Tour in a Suburb of Tokyo. J. Asian Rur. Stud., 4 (2): 241-254.

\begin{abstract}
This study explores the potential of one-off gardening experience tours for the reduction of mental stress of urban corporate workers. By using both medical and sociological data, it examines how the participants' preconceived images of farming and other factors may influence the stress-reducing effects of gardening activities. The examination of several salivary

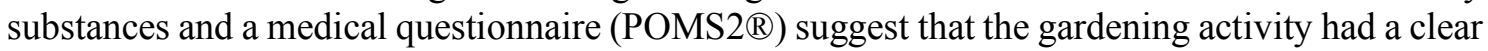
stress-reducing effect for most participants. It was also revealed that the stress-reducing effect was greater for those who have positive images of farming than those with negative images. This suggests that gardening activities may not necessarily be beneficial for all walks of life, depending on one's preconceived image of farming. At the same time, in order to evaluate the stress-reducing effect of the entire tour, there is a need to pay attention to aspects other than the gardening activity itself, in particular communication with the other participants as well as travel distances.
\end{abstract}

Keywords: stress reduction; urban corporate workers; gardening activity; image of farming

\section{Introduction}

Job-related stress is one of the chronic problems in present-day urbanized society. Urban corporate workers across the world have been suffering from a number of different types of stress-related diseases, including "burnout syndrome," which was defined by Freudenberger (1974) and is often found among workaholics; "apathy syndrome," in which workers lose interest in their jobs and interpersonal relationships with their colleagues; and "techno-stress syndrome," derived from maladaptation (as well as overadaptation) to information technology (La Torre, 2019). Highly advanced information technology, in particular, causes great stress due to the inhuman working environment characterized by continual interaction with machines, the gap between biorhythm and prolonged working hours both day and night, and endless global competition.

Stress-related mental and physical disorder is not limited to mere personal problems; it has a much wider social impact. It can induce social maladjestment (or social 
withdrawal in the worst cases) of the individual, leading to social instability and the dysfunction of the communities in each locality or workplace. At the same time, it also creates economic problems including decline in productivity and increase in medical expenses. Needless to say, depression and suicide caused by stress is a huge social loss. The Japanese Ministry of Health, Labor and Welfare announced in 2010 that the social loss caused by suicide and depression amounted to 2.7 trillion yen (MHLW 2010). From the late 2000s, policy makers in Japan started to pay serious attention to stress-related social problems. For instance, mental health supporting centers were established in each prefecture in 2008. In 2010, mental disability was legally recognized as a prescribed industrial disease. Furthermore, in 2014, the Labor Security and Hygiene Act was amended, requiring each company to conduct stress checks for its employees. This check system, however, is based only on a self-assessment by each employee, lacking concrete measures to reduce corporate workers' mental stress.

Recently, gardening has attracted increasing attention as a simple and effective measure to alleviate the stress of city dwellers. This is due in part to gardening or the farming activity being considered as having a variety of welfare functions, including improving mental health (Matsuo 2005; Ikegami 2013). Horticultural therapy is one of the practices which focuses on the therapeutic effects of gardening activities (Japan Horticultural Well-being Association 2002). However, as full-fledged horticultural therapy practices require continuous gardening activities for a certain period of time, they are difficult to practice for busy corporate workers in urban centers. This study, therefore, focuses on the potential of one-off gardening activities for reducing the stress of urban workers.

Studies on the stress-reducing effects of gardening have been made primarily from a medical viewpoint, by using several biomarkers as stress indicators (van den Berg and Custers 2011; NTT Data Institute of Management Consulting 2013). The physical and mental effects of gardening or other plant-related activities may vary widely, however, and are influenced by a wide range of personal factors that characterize each individual (Matsuo 2005). Among the various personal factors, this study focuses on the perception of farming held by each individual. As each participant may have different ideas and attitudes toward farming, it is unlikely that gardening activities have a uniform stressalleviating effect for all, regardless of their feelings about gardening work. Our hypothesis is that gardening activities may be effective in alleviating stress for those who have a positive impression of farming, while they may not be effective for those with negative images.

The aim of this paper is, therefore, to reveal the correlation between the stress-reducing effect of gardening activities for urban workers and their preconceived images of farming, by focusing on a one-day gardening experience tour. It also examines the relationship between stress reduction and job stress that workers experience in their workplaces. Such a study may provide some basic data which can be utilized for the planning of stress reduction programs for urban corporate workers, which can contribute not only to stress management in companies, but also to rural rivitalization through active green and medical tourism. Exploring optimum personal conditions to maximize the stress-reducing effect of gardening may also help us to deliberately target a group of workers, for whom gardening activities are likely to have the full stress-reducing effect.

This study is based on a joint research project between Juntendo University (the Laboratory of Palliative Medicine, Faculty of Medicine) and Kindai University 
(Laboratory of Environmental Policy, Faculty of Agriculture). This research was approved by the committee for biological ethics at the Faculty of Agriculture, Kindai University (No. 2016-15) and by the committee for research ethics of the Faculty of Medicine, Juntendo University (No. 2017106).

In the following section, we begin with an explanation of the methodologies and data collection. That will be followed by the analysis of medical and sociological data, based on the average scores of all the examinees. Finally, the examinees are divided into two groups according to their preconceived images of farming by using principal component analysis in order to examine the correlation between the stress-reducing effect and images of farming as well as other factors.

\section{Materials and Methods}

The field survey was carried out on the participants of a one-day gardening experience tour held at a farm park facility in Chiba Prefecture. The examinees are ten employees (six males and four females) belonging to the same company, and who voluntarily applied for the invitation to the tour. The age structure of the examinees is as follows: four individuals in their $20 \mathrm{~s}$, two in their $30 \mathrm{~s}$, one in their 40s, and three in their 50s. Table 1 shows the timetable for the tour, along with the weather conditions for that day. Participants gathered at Tokyo Station at 10:00 a.m. and left for the farm park in Chiba by bus. After lunch, they were informed in advance of the purpose and methodology of this study, along with how to handle personal information. The gardening work included making ridges, the binding of Chinese cabbage, and the harvesting of sweet potatoes.

Table 1. Timetable for the Farming Experience Tour in Chiba

\begin{tabular}{|c|c|c|}
\hline Date & & 19th December 2017 \\
\hline Weather* & & Cloudy (at 15:00) \\
\hline Temperature* & & $11.3{ }^{\circ} \mathrm{C}$ (at $\left.15: 00\right)$ \\
\hline \multirow{9}{*}{ Timetable } & 10:00 & Gather at Tokyo Station and Salivary test** \\
\hline & & Move to Chiba by bus \\
\hline & $12: 30-13: 30$ & Arrive at "The Farm" and Lunch \\
\hline & $13: 30-14: 00$ & Salivary test + POMS and sociological questionnaire \\
\hline & 14:30-15:30 & Gardening activity \\
\hline & $15: 30-16: 00$ & Salivary test + Sociological questionnaire \\
\hline & & Return to Tokyo by bus \\
\hline & $18: 30$ & Arrive at Tokyo Station \\
\hline & 18:30-19:00 & Salivary test + POMS questionnaire \\
\hline
\end{tabular}

Source: Authors.

Notes: * Weather and temperature provided hear were taken at the time the gardening activity took place. Temperature was cited from the Japan Weather Association website (https://tenki.jp/past/2017/12/amedas/3/15/).

**Saliva of examinees were collected by using Saliva Collection Aid Kit. 
The data used in this paper was obtained through (1) the collection of salivary substances before and after the gardening work, (2) a medical questionnaire survey (POMS2), and (3) a sociological questionnaire survey (Table 1). As for the saliva components, the concentrations of $\alpha$-amylase, cortisol, s-IgA (immunoglobulin), and oxytocin were measured. $\alpha$-amylase is one of the digestive enzymes that responds sensitively to physical stress. For example, it is known that it increases under the presence of acute stress caused for instance by examinations, speeches, mental arithmetic, and physical exercise. Cortisol is widely used as an indicator of chronic stress. The concentration of cortisol tends to be high in the morning for those who experience chronic stress due to their job, unemployment or divorce. Immunoglobulin has been used as an indicator of acute stress. Its concentration increases, for example, in mental arithmetic tasks and oral presentations (Izawa et al. 2007). Oxytocin is secreted by physical and mental contact with other people, and also works to promote positive and favorable bonds with others (Takahashi 2014).

In order to examine stress-reducing effects of the gardening tour from the viewpoint of emotional change, we employed POMS questionnaire (POMS2®), which is widely used as a reliable method to measure temporary changes in personal mood and emotions. There are seven sets of emotions designated in the questionnaire: six pairs of angerhostility, confusion-bewilderment, depression-dejection, fatigue-inertia, tension-anxiety, and vigor-activity, and a single item of friendliness (Heuchert and McNair 2012). TMD (Total Mood Disturbance) score is also calculated to examine the changes in negative emotions before and after the gardening activity.

Before the gardening activity, a sociological questionnaire survey was conducted to clarify the examinees' basic attributes, their image of farming, and factors of stress in their workplaces. Immediately after the farm work, a questionnaire survey was carried out again to understand the examinees' post-activity reactions to the tour.

Below, we examine (1) whether the gardening work itself had the stress-reducing effect for urban workers, and (2) whether there is any correlation between the stressreducing effect and the examinees' preconceived image of farming as well as other factors.

\section{Changes in Personal Mood and Salivary Substances}

This section examines the stress-reducing effect of the gardening activity by analyzing the data from POMS questionnaire and salivary test. Table 2 shows the average score and standard deviation of each item of POMS questionnaire for ten examinees before gardening work and after the entire tour, along with TMD score, a comprehensive index of negative emotions. This table shows that the scores of all negative sets of emotions decreased after the gardening work, whereas the scores of both positive sets increased. TMD decreased by $13 \%$, indicating that psychological stress was reduced after the entire tour. 
Table 2. Changes in POMS Scores

\begin{tabular}{|c|c|c|c|c|c|c|c|c|}
\hline & \multirow[b]{2}{*}{ Set of emotions } & \multicolumn{2}{|c|}{ Before gardening activity } & \multicolumn{2}{|c|}{ After the entire tour } & \multicolumn{3}{|c|}{ Changes } \\
\hline & & Average & $\begin{array}{l}\text { Standard } \\
\text { deviation }\end{array}$ & Average & $\begin{array}{l}\text { Standard } \\
\text { deviation }\end{array}$ & Average & $\begin{array}{l}\text { Standard } \\
\text { deviation }\end{array}$ & $\begin{array}{l}\text { Rate of } \\
\text { change }\end{array}$ \\
\hline \multirow{5}{*}{ Negative } & Anger-Hostility (AH) & 44.6 & 12.04 & 41.2 & 6.06 & $-3.4^{*}$ & 6.3 & $-8 \%$ \\
\hline & Confusion-Bewilderment (CB) & 47.4 & 10.77 & 40.80 & 8.55 & $-6.6^{*}$ & 6.3 & $-14 \%$ \\
\hline & Depression-Dejection (DD) & 46.5 & 8.66 & 42.5 & 4.67 & $-4.0^{*}$ & 19.0 & $-9 \%$ \\
\hline & Fatigue-Inertiaa (FI) & 43.9 & 9.91 & 43.5 & 6.62 & -0.5 & 6.5 & $-1 \%$ \\
\hline & Tension-Anxiety (TA) & 48.2 & 11.73 & 40.0 & 11.73 & $-8.2^{*}$ & 9.7 & $-17 \%$ \\
\hline \multirow{2}{*}{ Positive } & Vigor-Activity (VA) & 56.9 & 11.73 & 60.7 & 8.87 & +3.80 & 8.2 & $7 \%$ \\
\hline & Friendliness $(\mathrm{F})$ & 55.1 & 11.82 & 57.7 & 9.33 & +2.60 & 7.1 & $5 \%$ \\
\hline \multicolumn{2}{|c|}{ Total Mood Disturbance (TMD) } & 44.7 & 10.87 & 39.1 & 7.06 & -5.60 & 4.7 & $-13 \%$ \\
\hline
\end{tabular}

Source: Field survey.

Note: A Wilcoxon rank sum test (one of nonparametric statistical tests) was employed for the statistical test of the data . ${ }^{*}$ was significant at $5 \%$.

Next, the changes in saliva components before and after the gardening activity will be examined. Table 3 summarizes the changes in concentration of salivary components before and after the gardening work. As this table shows, among the average values of the four saliva components, $\alpha$-amylase and oxytocin increased after the gardening activity, while the remaining two substances, cortisol and immunoglobulin, decreased. The values of standard deviations for $\alpha$-amylase, oxytocin, and immunoglobulin suggest that the pattern of change of these three salivary substances varies widely between the individual examinees. The result of a Wilcoxon rank sum test indicates that these three substances are not significant at 5\%. Accordingly, it is difficult to determine if the gardening work had a similar stress-reducing effect for all the examinees, with a considerable variation for each. On the other hand, standard deviation is low in the case of cortisol, suggesting that the gardening work had the effect of reducing chronic stress for most examinees.

Table 3. Concentration of Salivary Substances before and after Gardening Activity (Average Value for Ten Examinees)

\begin{tabular}{cl|cccc}
\hline \multirow{2}{*}{ Measured salivary substance } & \multicolumn{4}{|c}{ Gardening activity } \\
\cline { 3 - 6 } & Concentration $(\mathrm{kIU} / \mathrm{L})$ & 29.1 & 32.8 & 3.7 & $+13 \%$ \\
\hline \multirow{2}{*}{$\alpha$-amylase } & Before & After & $\begin{array}{c}\text { Amount of } \\
\text { change }\end{array}$ & $\begin{array}{c}\text { Rate of } \\
\text { change }\end{array}$ \\
& Standard deviation & 15.63 & 16.67 & 16.47 & \\
\hline \multirow{2}{*}{ Cortisol } & Concentration $(\mu \mathrm{g} / \mathrm{dl})$ & 0.30 & 0.09 & $-0.21 *$ & $-70 \%$ \\
& Standard deviation & 0.26 & 0.22 & 0.22 & \\
\hline \multirow{2}{*}{ Oxytocin } & Concentration $(\mathrm{pg} / \mathrm{ml})$ & 29.24 & 49.74 & 20.5 & $+70 \%$ \\
& Standard deviation & 20.22 & 47.02 & 32.11 & \\
\hline \multirow{2}{*}{ s-lgA } & Concentration $(\mu \mathrm{g} / \mathrm{ml})$ & 36.66 & 31.18 & -5.48 & $-15 \%$ \\
\hline Immunoglobulin) & Standard deviation & 37.36 & 23.99 & 44.15 & \\
\hline
\end{tabular}

Source: Field survey.

Note: A Wilcoxon rank sum test (one of nonparametric statistical tests) was employed for the statistical test of the data . * was significant at $5 \%$. 


\section{An Analysis of Sociological Questionnaire Survey}

In this section, the results of sociological questionnaires taken before and after the gardening activity will be analyzed. For all the questions, the examinees were asked to mark the points based on a five-point grading scale. Regarding their native places, the examinees were asked whether they hailed from urban areas or the countryside (five points for urban extreme and one point for rural extreme). The average point was 3.3 with the standard deviation being 1.57. More than half of the examinees scored more than three points, while two scored one point, indicating that they hailed from rural areas.

Examinees were also asked whether they feel stress at their workplaces for each of six items or factors. Table 4 reveals that the item "too much work" gained the highest score, followed by "failures in work" and "relationships with colleagues" as the cause of stress. Scores vary between examinees for the items "too much work" and "relationships with colleagues" with relatively high values for standard deviation (Table 4).

Before the gardening activity, we also asked examinees their preconceived image of farming. They were asked to rate on a scale of one to five for twelve images of farming as shown in Table 5. The highest scores were marked for the image "Anticipating tasting harvested crops" and "Getting close to nature". For these two items, standard deviation is also small, indicating that there is little variation between each examinee. Conversely, the standard deviation of the other items is relatively large, indicating a considerable variation between the examinees. Undesirable images of farming such as "dirty" and "laborious" were given around three points, relatively high scores similar to those of most preferable images.

\begin{tabular}{|c|c|c|c|c|}
\hline \multicolumn{2}{|c|}{ Cause of stress } & Average score & \multicolumn{2}{|c|}{ Standard deviation } \\
\hline \multicolumn{2}{|l|}{ Too much work } & 3.2 & \multicolumn{2}{|l|}{1.62} \\
\hline \multicolumn{2}{|l|}{ Failures in work } & 2.4 & \multicolumn{2}{|l|}{0.97} \\
\hline \multicolumn{2}{|c|}{ Relationships with colleagues } & 2.3 & \multicolumn{2}{|l|}{1.57} \\
\hline \multicolumn{2}{|c|}{ Anxiety over stability of employment } & 2.2 & \multicolumn{2}{|l|}{1.40} \\
\hline \multicolumn{2}{|c|}{ Anxiety over the future of the company } & 2.0 & \multicolumn{2}{|l|}{1.33} \\
\hline \multicolumn{2}{|c|}{$\begin{array}{l}\text { Changes in position and role in the } \\
\text { workplace }\end{array}$} & 2.0 & 1.25 & \\
\hline \multicolumn{5}{|c|}{ Source: Field survey. } \\
\hline \multicolumn{3}{|c|}{ Images of farming } & Average score & Standard Deviation \\
\hline \multirow{2}{*}{ Undesirable images } & \multicolumn{2}{|l|}{ Laborious } & 3.2 & 1.32 \\
\hline & \multicolumn{2}{|c|}{ Dirty } & 2.8 & 1.55 \\
\hline \multirow{7}{*}{ Preferable images } & \multicolumn{2}{|c|}{ Anticipating tasting harvested crops } & 4.5 & 0.97 \\
\hline & \multicolumn{2}{|c|}{ Getting close to nature } & 4.4 & 0.84 \\
\hline & \multicolumn{2}{|c|}{ Reducing stress } & 3.4 & 1.65 \\
\hline & \multicolumn{2}{|c|}{ Fragrance of crops is attractive } & 3.1 & 1.66 \\
\hline & \multicolumn{2}{|c|}{ Landscape is attractive } & 3.1 & 1.20 \\
\hline & \multicolumn{2}{|c|}{$\begin{array}{l}\text { Observing plants' color and growth has } \\
\text { a therapeutic effect on me }\end{array}$} & 3.1 & 1.66 \\
\hline & \multicolumn{2}{|c|}{ A leisure requiring physical activities } & 2.6 & 1.51 \\
\hline \multirow{3}{*}{$\begin{array}{l}\text { Neither preferable or } \\
\text { undesirable }\end{array}$} & \multicolumn{2}{|c|}{$\begin{array}{l}\text { It is difficult to experience if one lives in } \\
\text { an urban area }\end{array}$} & 3.7 & 1.70 \\
\hline & \multicolumn{2}{|c|}{$\begin{array}{l}\text { Farming is familiar to me as I practice it } \\
\text { once in a while }\end{array}$} & 2.7 & 1.49 \\
\hline & \multicolumn{2}{|c|}{ Strong association with rurality } & 2.2 & 1.23 \\
\hline
\end{tabular}

Source: Field survey. 
Table 6 shows the ex-post evaluations of this farming experience tour by each item. The highest score was marked by the item "It was a good exercise", followed by "It was good to bring the harvested crops back home", both with a small standard deviation. The other items with a high score were "It was a good occasion to mingle with my colleagues" and "I felt relaxed amidst the natural environment". The items "It was good to bring the harvested crops back home" and "I felt relaxed amidst the natural environment" are similar to the preconceived images of farming which were given high scores ("Anticipating tasting harvested crops" and "Getting close to nature"). This indicates that the tour met the participants' expectations in terms of their preferable images of farming. Conversely, undesirable items such as "I hate gardening because it is a dirty work" and "Gardening is a laborious work" have very low average scores. This fact suggests that participants' unfavorable images of farming such as "dirty" and "laborious", both of which were given relatively high scores before the gardening work, improved after the activity.

Table 6. How the Participants Felt about the Farming Experience Tour

\begin{tabular}{l|c|c}
\multicolumn{1}{c|}{ Cause of stress } & Average score & Standard deviation \\
\hline It was a good exercise & 4.5 & 0.97 \\
It was good to bring the harvested crops back home & 4.4 & 0.70 \\
It was a good occasion to mingle with my colleagues & 4.2 & 1.32 \\
I felt relaxed amidst the natural environment & 4.0 & 0.94 \\
I got tired from moving by bus over the long distance & 4.0 & 0.94 \\
I could experience gardening work which I had been & 3.9 & 1.52 \\
unfamiliar with & & \\
Next time I want to join the tour with my family & 3.6 & 1.43 \\
members rather than with my colleagues & 2.3 & 1.34 \\
Farming is laborious work & 1.2 & 0.42 \\
No interest & 1.1 & 0.32 \\
I dislike farming work as it is dirty &
\end{tabular}

Source: Field survey.

It is also notable that the item "I got tired from moving by bus over the long distance" marked a relatively high score (Table 6). This clearly shows that the two-hour journey from Tokyo to Chiba was a stressful one. It is also worth noting that although there is great variation among the examinees, the score for "Next time I want to join the tour with my family members rather than with my colleagues" is relatively high, and there are several examinees who have given this item the highest scores (five points, see Table 13). This fact suggests that some participants may not have been overly relaxed with their colleagues, although the average satisfaction level for the entire tour was high, as much as 4.4 with little variation (standard deviation 0.52 ).

\section{Relationship between Images of Farming and Stress-reducing Effects}

\subsection{Classification of Examinees by Principal Component Analysis}

This section analyzes the correlation between the examinee's personal attributes, especially the images of farming, and the stress-reducing effects of the gardening activity. The first step is to categorize examinees according to their preconceived images of 
farming (five-grade scores for 12 items), by employing principal component analysis. Although an accumulated contribution rate of the first principal component and the second principal component is relatively low (63\%), the two principal components are likely to be enough for the present purpose of classifying examinees.

Table 7 shows the principal component load of each image of farming. As for the first principal component (PC1), the values of "Dirty" and "Laborious" are positive, while those of other images of farming are negative. People are inclined to avoid something "Dirty" and "Laborious" in general. Accordingly, the first principal component is characterized as an 'undesirable image of farming'. As for the second principal component (PC2), the values of "Farming is familiar to me as I practice it once in a while" is the largest and most negative. Accordingly, the second principal component is considered as 'familiarity to farming'.

Table 7. Principal component load for each image of farming

\begin{tabular}{l|c|c}
\hline \multicolumn{1}{c|}{ Images of farming } & $\begin{array}{c}\text { 1st principal } \\
\text { component }\end{array}$ & $\begin{array}{c}\text { 2nd principal } \\
\text { component }\end{array}$ \\
\hline Dirty & 0.56 & 0.75 \\
Laborious & 0.76 & -0.21 \\
Landscape is attractive & -0.53 & 0.42 \\
Observing plants' color and growth has a therapeutic effect on me & -0.84 & 0.11 \\
Getting close to nature & -0.29 & 0.35 \\
A leisure requiring physical activities & -0.81 & 0.30 \\
Reducing stress & -0.84 & 0.29 \\
Fragrance of crops is attractive & -0.89 & 0.05 \\
Anticipating tasting harvested crops & -0.58 & -0.23 \\
It is difficult to experience if one lives in an urban area & -0.58 & 0.66 \\
Farming is familiar to me as I practice it once in a while & -0.39 & -0.81 \\
Strong association with rurality & 0.47 & 0.68 \\
\hline
\end{tabular}

Source: Authors.

Table 8. Principal component score

\begin{tabular}{c|c|c}
\hline Examinee no. & $\begin{array}{c}\text { 1st principal } \\
\text { component }\end{array}$ & $\begin{array}{l}\text { 2nd principal } \\
\text { component }\end{array}$ \\
\hline 1 & -1.10 & 0.80 \\
2 & -1.34 & -1.09 \\
3 & 1.55 & 0.19 \\
4 & -0.53 & 0.57 \\
5 & 1.99 & -3.93 \\
6 & -0.20 & 0.64 \\
7 & 1.74 & 1.58 \\
8 & -2.00 & 1.36 \\
9 & 3.60 & 0.94 \\
10 & -3.73 & -1.06 \\
\hline
\end{tabular}

Source: Authors. 
Table 8 is the result of estimating the principal component scores of each examinee (from no. 1 to no. 10). Figure 1 was drawn according to Table 8 . Figure 1 displays a scatter plot of principal component scores for each examinee. Here, each examinee is plotted on a coordinate, with the first principal component (undesirable images on farming) on the horizontal axis and the second principal component (familiarity to farming) on the vertical axis. As for the first principal component, the higher the score one has (i.e. the further to the right on the horizontal axis), the stronger his or her unfavorable images. Regarding the second principal component, the higher the score one has (that is, the higher on the vertical axis), the greater his or her familiarity to farming.

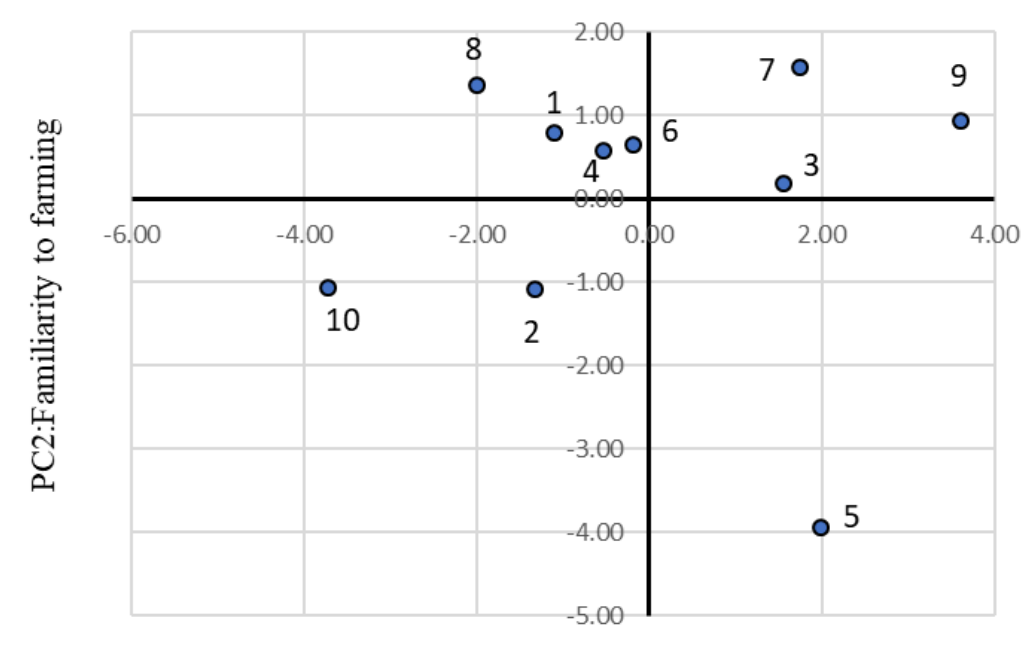

PC1: Undesirable image of farming

Figure 1: Scatter Chart for First and Secon Principal Components Source: Authors.

Figure 1 indicates that most cases are distributed near the horizontal axis except examinee no. 5. Since no. 5's images of farming may be strongly influenced by 'familiarity to farming' rather than an 'undesirable image of farming', this examinee (no. 5 ) will be excluded from the present analysis as an exceptional case.

As a result, two categories of examinees are found: one is a group of examinees with preferable images of farming (the left side of vertical axis on Figure 1), and the other is a group of those with undesirable images of farming (the right side of vertical axis on Figure 1). The former is composed of examinees nos. 1, 2, 4, 6, 8, and 10 (hereafter referred to as the "positive group"), while the latter is made up of nos. 3, 7 and 9 (the "negative group").

Table 9 shows the scores of images of farming for two groups. As this table shows, the scores for undesirable images of farming ("dirty" and "laborious") are higher in the negative group than in the positive group, in accordance with the group classification. On the other hand, scores for the images "Getting close to nature" and "Anticipating tasting harvested crops" are high in both groups. Scores for preferable images other than the above two items are higher for the positive group than those for the negative group. 
Table 9. Average Score of Images of Farming by Groups

\begin{tabular}{|c|c|c|c|c|c|c|c|c|c|}
\hline \multirow[b]{2}{*}{ Groups } & \multicolumn{2}{|c|}{ Undesirable images } & \multicolumn{7}{|c|}{ Preferable images } \\
\hline & Dirty & Laborious & $\begin{array}{l}\text { Getting } \\
\text { close to } \\
\text { nature }\end{array}$ & $\begin{array}{c}\text { Reducing } \\
\text { stress }\end{array}$ & $\begin{array}{c}\text { A leisure } \\
\text { requiring physical } \\
\text { activities }\end{array}$ & $\begin{array}{c}\text { Fragrance } \\
\text { of crops is } \\
\text { attractive }\end{array}$ & $\begin{array}{c}\text { Anticipating } \\
\text { tasting harvested } \\
\text { crops }\end{array}$ & $\begin{array}{l}\text { Observing plants' color } \\
\text { and growth has a } \\
\text { therapeutic effect on me }\end{array}$ & $\begin{array}{c}\text { Landscape } \\
\text { is } \\
\text { attractive }\end{array}$ \\
\hline Positive group & 2.33 & 2.50 & 4.50 & 4.50 & 3.33 & 4.17 & 4.83 & 4.17 & 3.50 \\
\hline Negative group & 4.33 & 4.00 & 4.67 & 2.00 & 1.67 & 1.33 & 3.67 & 1.67 & 3.00 \\
\hline Total average & 2.80 & 3.20 & 4.40 & 3.40 & 2.60 & 3.10 & 4.50 & 3.10 & 3.10 \\
\hline
\end{tabular}

\subsection{Stress-reducing Effect by Group}

Table 10 indicates the changes in concentration of salivary substances (average value) before and after the gardening work for each of the two groups. The concentration of $\alpha-$ amylase increased in both the positive and negative groups. On the other hand, cortisol was reduced considerably by $75 \%$ in the positive group and by $54 \%$ in the negative group, suggesting a slightly greater stress-reducing effect for the positive group. While immunoglobulin decreased by $49 \%$ in the positive group, it more than doubled in the negative group, suggesting that the stress-reducing effect is considerably greater among the positive group than the negative group. With regard to oxytocin, the rate of increase in the positive group $(+86 \%)$ is significantly higher than that in the negative group $(+7 \%)$. This fact can be interpreted as indicating that the effect of reducing stress was greater in the positive group than in the negative group. The increase of oxytocin in the positive group may be related to the fact that communication was promoted during the gardening work according to the author's observation. Thus, both acute (immunoglobulin) and chronic (cortisol) stress were reduced for the positive group, and chronic stress decreased in the negative group, suggesting that gardening work may reduce chronic stress regardless of one's image of farming. In contrast, an increase in immunoglobulin for the negative group suggests the possibility that some acute stress might have occured.

Table 10. Changes in Salivary Substances before and after Gardening Work by Groups (Average, $\mathbf{n}=9$ )

\begin{tabular}{c|cc|cc|cc|cc}
\hline \multirow{2}{*}{$\alpha$-amylase } & \multicolumn{2}{c|}{ Cortisol } & \multicolumn{2}{c|}{$\begin{array}{c}\text { s-lgA } \\
\text { (Immunoglobulin) }\end{array}$} & \multicolumn{2}{c}{ Oxytocin } \\
\cline { 2 - 9 } & $\begin{array}{c}\text { Amount of } \\
\text { change } \\
(\mathrm{kIU} / \mathrm{L})\end{array}$ & $\begin{array}{c}\text { Rate of } \\
\text { change }\end{array}$ & $\begin{array}{c}\text { Amount of } \\
\text { change } \\
(\mu \mathrm{g} / \mathrm{dl})\end{array}$ & $\begin{array}{c}\text { Rate of } \\
\text { change }\end{array}$ & $\begin{array}{c}\text { Amount of } \\
\text { change } \\
(\mu \mathrm{g} / \mathrm{ml})\end{array}$ & $\begin{array}{c}\text { Rate of } \\
\text { change }\end{array}$ & $\begin{array}{c}\text { Amount of } \\
\text { change } \\
(\mathrm{pg} / \mathrm{ml})\end{array}$ & $\begin{array}{c}\text { Rate of } \\
\text { change }\end{array}$ \\
\hline Posiive group & 3.33 & $+11 \%$ & -0.26 & $-75 \%$ & -23.67 & $-49 \%$ & 32.08 & $+86 \%$ \\
Negative group & 4 & $+16 \%$ & -0.12 & $-54 \%$ & 28.55 & $+136 \%$ & 1.39 & $+7 \%$ \\
\hline
\end{tabular}

Source: Field survey.

Next, let us examine the examinees' reaction to the entire tour by comparing the two groups. Table 11 shows the average scores for each item of specific impressions on the tour for each of the two groups. The first thing to note from the viewpoint of communication is that the scores for the item "It was a good occasion to mingle with my colleagues" is high in the positive group. This may have led to the secretion of oxytocin through communication with colleagues during the farm work. It is also notable that the item "Next time I want to join the tour with my family members rather than with my colleagues" was given a higher score in the positive group rather than in the negative 
group. On the other hand, in the negative group, the fact that the negative items such as "I dislike farming work as it is dirty", "Farming is laborious work", and "No interest" are slightly higher than in the positive group. This may have related to the lower stressreducing effect for the negative group.

Table 11. Average Score for Ex-post Impression of the Tour

\begin{tabular}{l|cccccccccc}
\hline & $\begin{array}{c}\text { Good } \\
\text { occasion }\end{array}$ & $\begin{array}{c}\text { Good } \\
\text { experience }\end{array}$ & Relaxed & $\begin{array}{c}\text { Harvested } \\
\text { crops }\end{array}$ & $\begin{array}{c}\text { Family } \\
\text { preference }\end{array}$ & $\begin{array}{c}\text { Long time } \\
\text { movement }\end{array}$ & $\begin{array}{c}\text { Good } \\
\text { exercise }\end{array}$ & $\begin{array}{c}\text { Dislike } \\
\text { farming }\end{array}$ & $\begin{array}{c}\text { Laborious } \\
\text { work }\end{array}$ & $\begin{array}{c}\text { No interest } \\
\text { Positive group }\end{array}$ \\
4.67 & 4.17 & 4.00 & 4.17 & 4.17 & 3.83 & 4.33 & 1.00 & 1.83 & 1.00 \\
Negartive group & 3.67 & 3.67 & 4.00 & 4.67 & 3.33 & 4.33 & 4.67 & 1.33 & 2.67 & 1.67 \\
\hline Total average & 4.20 & 3.90 & 4.00 & 4.40 & 3.60 & 4.00 & 4.50 & 1.10 & 2.30 & 1.20 \\
\hline
\end{tabular}

Source: Field survey.

Note: Full texts of abbreviated form are as follows. Good experience; I could experience gardening work which I had been unfamiliar with. Good occasion; It was a good occasion to mingle with my colleagues. Laborious work; Farming is laborious work. Relaxed; I felt relaxed amidst the natural environment. Long time movement; I got tired from moving by bus over the long distance. Harvested crops; It was good to bring back harvested crops. Dislike gardening; I dislike farming work as it is dirty. Family preference; Next time I want to join the tour with my family members rather than with my colleagues. Good exercise; It was a good exercise.

\subsection{Stress-reducing Effects by Each Individual Examinee}

This section examines the relationship between the personal factors (causes of job stress, reaction to the tour) of each individual and the changes in saliva components. Here, we focus on two salivary substances, immunoglobulins and oxytocin, which displayed a considerable difference between the members of the positive and negative groups (see Table 10). Table 12 shows the scores of stress factors at their place of work and the amount of change for immunoglobulin and oxytocin for each examinee. According to the table, examinees nos. 2 and 8, both belonging to the positive group, had high scores in the items "I feel stress in my workplce" and "too much work (as one of the causes of job stress)". It should be noted that immunoglobulin decreased for these two cases. On the other hand, two examinee (nos. 4 and 8), with a higher score in "relationships with colleagues (as one of the causes of job stress)", had a significant increase in oxytocin. This suggests that oxytocin may have been secreted because the two, who usually feel stress in the interpersonal relationships with co-workers, were able to communicate with their colleagues through gardening activity in a way significantly different from the usual scenario. For the examinees in the negative group, an apparent relationship between the scores for the stress factors and the saliva component could not be found. 
Published by Hasanuddin University and Asian Rural Sociology Association

\begin{tabular}{|c|c|c|c|c|c|c|c|c|c|c|}
\hline & \multirow{2}{*}{$\begin{array}{c}\text { Examinee } \\
\text { no. }\end{array}$} & \multirow{2}{*}{$\begin{array}{l}\text { I feel stress in } \\
\text { my workplace }\end{array}$} & \multirow[b]{2}{*}{$\begin{array}{l}\text { Too much } \\
\text { work }\end{array}$} & \multirow[b]{2}{*}{$\begin{array}{l}\text { Relationship } \\
\text { s with } \\
\text { colleagues }\end{array}$} & \multicolumn{2}{|c|}{ Causes of stress } & \multirow[b]{2}{*}{$\begin{array}{l}\text { Anxiety over } \\
\text { stability of } \\
\text { employment }\end{array}$} & \multirow[b]{2}{*}{$\begin{array}{c}\text { Changes in } \\
\text { position and role in } \\
\text { the workplace }\end{array}$} & \multicolumn{2}{|c|}{$\begin{array}{c}\text { Change in Salivary } \\
\text { substance }\end{array}$} \\
\hline & & & & & $\begin{array}{c}\text { Failure in } \\
\text { work }\end{array}$ & $\begin{array}{l}\text { Anxiety over } \\
\text { the future of } \\
\text { the company }\end{array}$ & & & $\begin{array}{l}\text { S-IgA } \\
(\mu \mathrm{g} / \mathrm{ml})\end{array}$ & $\begin{array}{l}\text { Oxytocin(p } \\
\text { g/ml) }\end{array}$ \\
\hline \multirow{6}{*}{$\begin{array}{l}\text { Positive } \\
\text { group }\end{array}$} & 1 & 2 & 4 & 1 & 2 & 2 & 4 & 2 & -50.81 & -14.93 \\
\hline & 2 & 4 & 5 & 1 & 3 & 2 & 3 & 3 & -9.64 & -5.34 \\
\hline & 4 & 3 & 2 & 4 & 2 & 3 & 2 & 2 & 4.27 & 61.70 \\
\hline & 6 & 2 & 4 & 1 & 3 & 1 & 1 & 1 & -6.85 & 61.94 \\
\hline & 8 & 4 & 5 & 4 & 3 & 3 & 2 & 4 & -104.24 & 71.92 \\
\hline & 10 & 1 & 1 & 1 & 1 & 1 & 1 & 1 & 25.26 & 17.20 \\
\hline \multirow{3}{*}{$\begin{array}{c}\text { Negative } \\
\text { group }\end{array}$} & 3 & 3 & 3 & 2 & 4 & 1 & 2 & 1 & 35.84 & -2.81 \\
\hline & 7 & 1 & 1 & 1 & 2 & 1 & 1 & 1 & 1.72 & 6.49 \\
\hline & 9 & 2 & 2 & 3 & 1 & 1 & 1 & 4 & 48.09 & 0.51 \\
\hline $\begin{array}{l}\text { Total } \\
\text { average }\end{array}$ & & 2.6 & 3.2 & 2.3 & 2.4 & 2 & 2.2 & 2 & -5.48 & 20.50 \\
\hline
\end{tabular}

Source: Field survey.

Table 13 below shows the scores for the ex-post impressions of the gardening tour and the amount of change in immunoglobulin and oxytocin for each individual. For the positive group, immunoglobulin increased in two examinees (nos. 4 and 10). It is notable that both gave the highest scores for items "I could experience gardening work which I had been unfamiliar with," "I got tired from moving by bus over the long distance," "Next time I want to join the tour with my family members rather than with my colleagues," and "It was good to bring the harvested crops back home". This fact may suggest that they felt stress in the tour because they were not familiar with the farm work, and also due to the long travel distance as well as their relationships with colleagues. Examinees who had an increased secretion of oxytocin (nos. 4, 6, 8, and 10) scored high in the items "Next time I want to join the tour with my family members rather than with my colleagues," "It was a good exercise," and "It was good to bring the harvested crops back home." On the contrary, in the negative group, no remarkable relationship could be found between the impression of the tour and the changes in saliva components.

\begin{tabular}{|c|c|c|c|c|c|c|c|c|c|c|c|c|c|}
\hline & \multirow{2}{*}{$\begin{array}{c}\text { Examinee } \\
\text { no. }\end{array}$} & \multicolumn{10}{|c|}{ Impression after gardening work } & \multicolumn{2}{|c|}{$\begin{array}{c}\text { Change in Salivary } \\
\text { substance }\end{array}$} \\
\hline & & $\begin{array}{c}\text { Good } \\
\text { experience }\end{array}$ & $\begin{array}{c}\text { Good } \\
\text { occasion }\end{array}$ & $\begin{array}{c}\text { Laborious } \\
\text { work }\end{array}$ & Relaxed & $\begin{array}{l}\text { Long time } \\
\text { movement }\end{array}$ & $\begin{array}{l}\text { Harvested } \\
\text { crops }\end{array}$ & $\begin{array}{c}\text { No } \\
\text { interest }\end{array}$ & $\begin{array}{l}\text { Dislike } \\
\text { farming }\end{array}$ & $\begin{array}{l}\text { Family } \\
\text { preference }\end{array}$ & $\begin{array}{l}\text { Good } \\
\text { exercise }\end{array}$ & $\begin{array}{c}\text { S-lgA } \\
(\mu \mathrm{g} / \mathrm{ml})\end{array}$ & $\begin{array}{c}\text { Oxytocin } \\
\text { (pg/ml) }\end{array}$ \\
\hline \multirow{6}{*}{$\begin{array}{l}\text { Positive } \\
\text { group }\end{array}$} & 1 & 5 & 5 & 2 & 4 & 3 & 4 & 1 & 1 & 3 & 2 & -50.81 & -14.93 \\
\hline & 2 & 2 & 5 & 1 & 4 & 4 & 3 & 1 & 1 & 4 & 4 & -9.64 & -5.34 \\
\hline & 4 & 5 & 4 & 2 & 3 & 5 & 5 & 1 & 1 & 5 & 5 & 4.27 & 61.70 \\
\hline & 6 & 5 & 5 & 3 & 4 & 4 & 4 & 1 & 1 & 3 & 5 & -6.85 & 61.94 \\
\hline & 8 & 3 & 4 & 2 & 4 & 2 & 4 & 1 & 1 & 5 & 5 & -104.24 & 71.92 \\
\hline & 10 & 5 & 5 & 1 & 5 & 5 & 5 & 1 & 1 & 5 & 5 & 25.26 & 17.20 \\
\hline \multirow{3}{*}{$\begin{array}{l}\text { Negative } \\
\text { group }\end{array}$} & 3 & 5 & 5 & 5 & 5 & 5 & 5 & 2 & 1 & 3 & 5 & 35.84 & -2.81 \\
\hline & 7 & 5 & 5 & 2 & 5 & 4 & 4 & 2 & 2 & 2 & 5 & 1.72 & 6.49 \\
\hline & 9 & 1 & 1 & 1 & 2 & 4 & 5 & 1 & 1 & 5 & 4 & 48.09 & 0.51 \\
\hline \multicolumn{2}{|c|}{ Total average } & 3.9 & 4.2 & 2.3 & 4 & 4.0 & 4.4 & 1.2 & 1.1 & 3.6 & 4.5 & -5.48 & 20.50 \\
\hline
\end{tabular}

Source: Field survey.

Note: For full texts of abbreviated form, see note to Table 11. 


\section{Conclusions}

We have so far examined the stress-reducing effect of the one-day gardening tour for urban corporate workers. Comparison of the average values of each salivary substance before and after the gardening work indicated that, overall, the activity had a stressreducing effect, with the exception of $\alpha$-amylase, an indicator of acute stress, which slightly increased on average. The POMS questionnaire survey also showed a decline of negative mood after the entire tour. At the same time, an analysis based on classification of examinees according to their images of farming indicates that the stress-reducing effect was greater among those within the positive group who had preferable images of farming than among those in the negative group. This result is in accordance with our original hypothesis.

Some data suggest the importance of understanding the gardening work and the entire tour in terms of communication process. It was notable that examinees who felt stress in interpersonal relationships with their co-workers in daily life secreted much oxytocin after the gardening work, in which they may have had a relationship with their colleagues in a friendly and relaxed manner. At the same time, the high scores for the one item of the ex-post reactions, "Next time I want to join the tour with my family members rather than with my colleagues," also indicates that "with whom" they work is an important factor which greatly affects the stress-reducing effect, along with the content of the gardening work itself. Another notable point is that the long travel distance to the farm park was stressful for many examinees.

From the above results, we may have to pay attention to the following points when we plan to organize gardening experience events aimed at reducing the stress of corporate workers: (1) we have to target those who have preferable images of farming; (2) they should be allowed to accompany their family members; and (3) it is better to set a nearby venue with a short travel time. Otherwise, a multiple-day gardening experience tour may be recommended over the one-day gardening experience tour.

\section{References}

Freudenberger, H. J. (1974). Staff burnout, Journal of Social Issues, 30: 159-165.

Heuchert, J. P. and D. M. McNair (2012). Profile of Mood States -second edition (POMS2). Toronto.

Ikegami, K. (2013). Agriculture's Potential for Well-being. Tokyo: Nosangyoson Bunka Kyokai (in Japanese).

Izawa, S., K. Shirotsuki, N. Sugaya, N. Ogawa, K. Suzuki, and S. Nomura (2007). The application of saliva to an assessment of stress: procedures for collecting and analyzing saliva and characteristics of salivary substances. Japanese Journal of Complementary and Alternative Medicine, 4 (3): 91-101 (in Japanese).

Japan Horticultural Well-being Association (ed.) (2002). A Guide to horticultural wellbeing. Tokyo: Soshin-sha (in Japanese).

La Torre, G., Esposito, A., Sciarra, I. (2019). Definition, symptoms and risk of technostress: a systematic review. International Archives of Occupational and Environmental Health, 92, 13-35.

Matsuo, E. (2005). An Exhortation to Social Horticultural Science. Tokyo: Nosangyoson Bunka Kyokai (in Japanese). 
MHLW (Ministry of Health, Labor and Welfare) (2010). Press Release: Economic Benefits of Measures against Suicide and Depression (Social Loss Caused by Suicide and Depression). (https://www.mhlw.go.jp/stf/houdou/2r9852000000qvsy.html, accessed on 11 April 2020).

NTT Data Institute of Management Consulting. (2013). A Report of the Study on Gathering Evidences of the Relations between Gardening and Health. A survey commissioned by the Ministry of Agriculture, Forestry, and Fisheries, 2012 (in Japanese).

Takahashi, T. (2014). Human Becomes Healthy by Loving Others: Oxytocin, the Hormone of Affection. Tokyo: Chido-shuppan (in Japanese).

van den Berg, A. E. and M. H. G. Custers. (2011). Gardening promotes neuroendocrine and affective restoration from stress, Journal of Health Psychology, 16 (1): 3-11. 